\title{
An essay on financial information in the era of computerization
}

\begin{abstract}
This article deals with the increasing computerization of the financial markets and the consequences of such as process on our ability to collect information about financial prices. The concept of information is at the heart of financial economics simply because this notion is a precondition for all investments. Since financial prices characterize an agreement on a transaction between two counterparties, they understandably became a key informational indicator for decision. This article will analyse the increasing computerization of financial sphere by discussing the recent emergence of what is called a "flash crash" and its impact on the traditional ways of collecting information in finance (technical analysis, fundamental analysis and statistical approach). I argue that the growing computerization of financial markets generated a "hyper-reality" in which financial prices do not refer to "something" anymore implying a revision of our usual way of defining/using the notion of information.
\end{abstract}

Keywords: Computerization of financial markets, information, hyper-reality, technical analysis, fundamental analysis and financial mainstream

\section{Introduction}

Financial markets play an important role in the allocation of resources in our economies and, in this perspective, the way information is generated and distributed became a crucial issue. This article deals with the increasing computerization of the marketplaces and the consequences of such as process on our ability to collectltreat information about financial prices. Because the concept of information is a precondition for all investments, this notion is at the heart of financial economics. In this context, the big question for decision makers is to know on what kind of knowledge they will base their decisions. Financial prices characterize an agreement on a transaction between two counterparties, consequently, they understandably became a key informational indicator for investment. As Muniesa (2007, p.378) explained it, "the price is the sign and the value is the thing of which the price is the sign". Afterwards, the author rightly asked: signs of what? What do prices refer to? The cornerstone of the literature (Mackenzie, 2006; Lepinay, 2007a, 2007b; Karl, 2013; Muniesa, 2007; 2014) dealing with the computerization of financial markets usually study these questions 
through the lens of the operationalization of knowledge. Muniesa $(2014$, p.7) talked about "reflexive modernization" or "performative utterances" to characterize this corpus studying how financial knowledge is materialized into practices $^{1}$. Muniesa (2014) proposed an interesting map of this literature that he decomposed into four problems:

"The first is about description, about the kind of think that a description produces. The second is about the simulacrum, about its truth and effect. The third is about provocation, about what is means to say that reality is really real when it is provoke, and hence realized. The fourth is about explicitness, about what it is for reality to accommodate explication" Muniesa (2014, p.17).

By dealing with some consequence of the algorithmization of financial transactions for the way we think the concept of information, this paper is more about the explicitness of this phenomenon: what is for financial information to implement (and accept) such phenomenon? Specifically, I will discuss how the operationalization (i.e. computerization) of a specific way of conceptualizing (i.e. efficient market hypothesis) the market led to the emergence of un-thought consequences that, a posteriori, contrast with the assumptions of the conceptual framework used in the computerization. Computers played a key role in this process. Through their ability to rationalizelrecord all kinds of transactions, computers contributed to the growing financialization of society. By financialization, I mean here the extension of the financial economics logics to other areas of knowledge. Generally speaking, financialization refers to a broad phenomenon dealing with deregulation, importance of shareholders and the development of information technology ${ }^{2}$. This reality has been gradually developed through the implementation of a particular financial knowledge. As Segot-Lagoarde (2016, p.2) explained it, despite "the financial world may turn out to be objective; in order to exist as such, it had to be provoked by financial theory in the first place". This article will only focus on one aspect of this financialization: the importance of information technology and its impact on the key notion of information in finance.

After having presented the three major ways of collecting information on financial markets (technical analysis, fundamental analysis and statistical analysis), I will discuss the increasing computerization of financial sphere by discussing the recent emergence of what is called a "flash crash". Afterwards, I will analyse the major impact of this evolution on the three ways of collecting information evoked above. In conclusion, I argue that the growing computerization of financial markets

\footnotetext{
${ }^{1}$ For a more general literature (i.e. not dealing only with financial markets), see Latour (1987); Cartwright (1999) and Galison (2007).

${ }^{2}$ See Lagoarde-Segot (2016) for further details on this phenomenon.
} 
generated a "hyper-reality" in which financial prices do not refer to "something" anymore implying a revision of our usual way of defining/using the notion of information.

\section{Prices and information}

When investment decisions have to be taken, people usually implement a specific analysis to collect information about financial markets. Roughly speaking, three major approaches can be presented regarding this collect of information for investment: technical analysis, fundamental analysis and statistical analysis. The next sub-section will present these three well-known ways of collecting information for an investment decision making process. After having emphasized the implicit assumptions used by these approaches in terms of information, I will discuss, later in this article, the impact of the growing computerization of the financial industry on these three methods.

\section{II.1). Joining the plots: Technical Analysis}

Technical analysis refers to the identification of visual patterns that could help traders to give a meaning to the financial reality. This practice is well-known by traders even though it is not used by all of them ${ }^{3}$. Generally speaking, technical analysis is a method based on the observation of the historical evolution of assets' prices and it tries to induce the future trend through a visual analysis ${ }^{4}$. This technique dates back from the late $1800 \mathrm{~s}$ when Charles $\mathrm{H}$. Dow introduced it as a market indicator in the Wall Street Journal ${ }^{5}$. Since then, it has been extensively used by financial actors (Park and Irwin, 2004). Although technical analysis includes a variety of conceptual tools (oscillators, moving average, etc.) ${ }^{6}$, it is epistemologically founded on patterns recognition and repetition (Bulkowski, 2005): when a trend has been established, the price movement is more likely to be in the same direction in the future. In terms of information, this approach is also based on the idea that all information that could affect a particular company is directly included in the indicators given by the chart. In this context, prices are assumed to capture all the complexity of financialleconomic reality. The repetitive

\footnotetext{
${ }^{3}$ Let us mention that technical analysis is not used by all traders. Often this technique is combined with other financial techniques as for example, a quantitative approach and/or a fundamental analysis.

${ }^{4}$ Preda (2009) explained that methods of chartism emerged in the 1900s but this technique became firmly established in the 1930s when "several organizations sold it as a product to brokerage house and several publications (books and magazines) promoted it to investors" (Preda, 2009, p.157). At that time, we could also find academic publications enhancing technical analysis - see, for example, Hamilton (1922), Schultz (1925) or Rhea (1932).

${ }^{5}$ But the justification of this method found its roots in astronomy and geometry (Gann 1923) by recording all historical prices of securities to reason out some recommendations in terms future movements of the market. ${ }^{6}$ All these concepts are tools for analysis the repetition of identified patterns (for further details about these conceptual tools, see Bulkowski, 2005).
} 
nature of price movements is attributed to market psychology: the market is considered to be so complex that the only way of studying the market feeling is to focus on the past evolution of prices because market participants are assumed to provide a consistent reaction to similar market stimuli over time.

Technical analysis is based on a visual macro-perspective which is supposed to describe phenomenologically the complexity of financial markets. Methodologically speaking, this method assumes three prerequisites: 1) Financial prices evolve by following recurrent patterns, 2) Financial prices are all-inclusive and 3) The future must reflect the past or, to put it another way, history will repeat itself. Actually, technical analysts do not seek for causality in the visual patterns they identified, they rather use them as anticipation of what the majority opinion will be about the future evolution of the market ${ }^{7}$. These methodological beliefs have generated a lot of debates in finance (Cootner, 1964; Hoffland, 1967; Leigh, 2002). Although technical analysis, also called "chartism", has been a part of financial practices for many decades (Park and Irwin, 2004), this way of collecting information has not received the same level of academic acceptance as more traditional approach as fundamental analysis (study of economic factors that influence financial prices) or quantitative methods (statistical analysis of financial prices) ${ }^{8}$. Indeed, there exists an old debate (that began in the 1960s) between authors from statistical approach and technical analysts (Hoffland, 1967). Technical analysis is founded on visual metaphors referring to visual information (patterns recognition) in opposition to the written information (i.e. knowledge based on the mathematical language enhanced by academic finance, Salomon, 1979) ${ }^{9}$. However, although these critical arguments used by academic finance, technical analysis is still very used in practice by experts (Oberlechner, 2001; Park and Irwin, 2004; Schinckus and Christiansen, 2012) but also by no experts (Sewell, 2008) ${ }^{10}$. This practical importance of technical analysis must not be underestimated and despite the existence of a critiques corpus, technical analysis remains a major way of collecting information for a lot of investment decisions makers. In such as context,

\footnotetext{
${ }^{7}$ This way of dealing with information echoes to the contest of beauty that Keynes evoked in the chapter 12 of his General Theory (Keynes, 1937). See Orlean (2008) for further details on this point.

${ }^{8}$ I will present these two perspectives in the next sections.

${ }^{9}$ This point explains why technical analysis is not well accepted by academic finance which often considers that this approach is too interpretative 9 and should be a part of "folklore" or "mythology". Cootner's book (1964) was one of the first publications used by the proponents of financial economics to define the discipline. In his book dedicated to the quantitative approach in finance, Cootner asserted that "Academic studies have proven to be more sceptical about the folklore of the market place than those of the professional practitioners. To several of the authors represented in this volume the 'patterns' described by some market analysis are mere superstitions. Julian Huxley has argued that mythology, religion, and superstition all flourish when men have to make decisions about matters over which they have no control." See Cootner (1964, p.1).

10 This widespread use has led to an institutionalization of this technique since there is the International Federation of Technical Analysts. In the United States, for example, chartists can be represented by the Market Technician Association (MTA) or the American Association of Professional Technical Analysts (AAPTA). In the UK, the Society of Technical Analyst (STA) promotes this approach by offering several kinds of trainings. For further information about the existing national societies, see http://www.ifta.org/developing-societies/.
} 
I will discuss, in the last part of this article, the consequences of a growing computerization on this technique.

\section{II.2) Look elsewhere! A Fundamental Analyst point of view}

Fundamental analysis is another well-known way of collecting information about financial prices. Precisely, this approach attempts to determine the real value of financial assets in relation to key value-drivers that are very often associated with accounting data. The core assumption of fundamental analysis is the belief that the accounting stock value determines the financial prices. This perspective contrasts with the technical analysis presented above since it considers that the key information for investment cannot be directly found in financial prices. Investment decisions have to be founded on the analysis of the systematic recording of companies' economic activity. So doing, fundamental analysis focuses on the identification of a set of fundamentals (growth, inventories, earnings etc.) whose complementary analysis is supposed to reveal the intrinsic value of a financial asset ${ }^{11}$.

Fundamental analysis is based on the economic intuition according to which financial prices result from a valuation of the economic activity (recorded into accounting statements) of companies. Despite its obvious common sense, fundamental analysis generates a lot of debates regarding the selection of valuedrivers indicators (Lev and Thiagarajan, 1993; Allen, 1999; Power, 2010). Indeed, the issue related to the identification of the most appropriate factor(s) to estimate the value of a stock is still debated in the literature (Power, 2010). In the same vein, several authors (Abarbanell and Bushee, 1997; Allen, 1999) criticized the back-forward dimension usually implemented by fundamental analysts who consider that the value of stocks can be induced from past activities of companies. So doing, this approach does not integrate other very important aspects of contemporary finance such as the speculative nature of markets or the crowd movements (i.e. mimetic behaviours, public opinion effect etc.) regularly observed on these markets. In terms of practices, fundamental analysis is well-known and widely used simply because this method derived from financial statements analysis taught in every business schools in the world (Power, 2010) ${ }^{12}$. By assuming that the key information related to investment decisions can be induced from accounting statements, fundamental analysis also contrasts with the financial mainstream that is rather based on statistical/mechanical method.

\footnotetext{
${ }^{11}$ It is worth mentioning that these key value-drivers are often associated with an analysis of macroeconomic variables (annual change of GDP, price indexes, etc.) in order to strengthen the link with economic context in which companies issuing financial assets are operating.

12 This approach is also promoted (and taught) by almost all associations of investors/analysts such as the American Association of Individual Investors, the Australian Association of Investor or the famous Chartered Alternative Investment Analyst (CAIA).
} 
Fundamental analysis remains a very important way of collecting information about the financial markets and the last section of this paper will analyse the impact of the computerization of financial markets on this approach.

\section{II.3) The financial countdown or the Statistical Analysis Approach}

The third way of collecting information about financial prices comes from academic finance. Financial economics became a field of research in the 1960s when American universities were taking a growing interest in American financial markets and when new statistical tools became available. As Jovanovic (2008) and Poitras (2009) explained it, academic finance roots its institutional birth in three elements ${ }^{13}: 1$ ) access to the tools of modern probability theory; 2 ) a new scientific community that extended the analysis framework of economics to finance; and 3) the creation of new empirical data. All these three elements were observed in the 1960 s while, prior this decade, finance taught in business school was very practical and far from what became the modern financial theory. During the 1960s and 1970s, a new community progressively emerged in the American business schools. Members of this new scientific community gradually shared common tools, references, and problems thanks to new textbooks, to seminars, and to scientific journals ${ }^{14}$. (Jovanovic 2008, Fourcade and Khurana 2009).

Another crucial advance contributed to the emergence of financial economics: computers allowing the creation of databases were more and more used as "bookkeeping machines" recording data on phenomena. The creation of empirical databases triggered a spectacular development of financial econometrics. This development also owed much to the scientific criteria propounded by the new community of researchers, who placed particular importance on statistical tests. At the time, econometric studies revealed very similar observation regarding the evolution of stock-market variations: they appear to be randomly distributed. The 1960s witnessed the emergence of what we call today quantitative finance that is based on the probabilisticlstatistical treatment of financial prices whose degree of randomness became key information for investment decisions. In this context, financial data are assumed to follow a normal (Gaussian) distribution whose standard deviation is associated with financial risk ${ }^{15}$. The use of statistical tools combined with the famous efficient market hypothesis (initially formulated by Fama in 1965) provides a coherent and mechanical framework for investment

\footnotetext{
${ }^{13}$ On the emergence of financial economics see Jovanovic (2008, 2009b, a), MacKenzie (2006) and Whitley (1986).

${ }^{14}$ The two journals that had published articles in finance, the Journal of Finance and the Journal of Business, changed their editorial policy during the 1960s: both started publishing articles based on modern probability theory and on modelling (Bernstein 1992, 41-44, 129).

${ }^{15}$ Markowitz (1952) was the first to propose such as association but is has gradually been generalized in the 1960s.
} 
analysis \decision. More precisely, this efficient market hypothesis, in its general acceptation, is often associated with the idea that all public information about securities is already reflected in their prices. Fama justified this claim by assuming the existence of different agents and behaviours on financial markets. According to him,

\begin{abstract}
"there is no strong reason to expect that each individual's estimates of intrinsic values will be independent of the estimates made by others (i.e., noise may be generated in a dependent fashion). For example, certain individuals or institutions may be opinion leaders in the market. That is, their actions may induce people to change their opinions concerning the prospects of a given company" (Fama, 1965, p. 37).
\end{abstract}

In other words, Fama assumed the existence of two kinds of traders: "sophisticated traders" and normal ones. In this perspective, the sophisticated traders, due to their skills, make a better estimate of the intrinsic/fundamental value than other agents do by using all available information. So doing, these wellinformed traders will have a significant influence on the market. Fama explained that, "although there are sometimes discrepancies between actual prices and intrinsic values, sophisticated traders in general feel that actual prices usually tend to move toward intrinsic values" (1965, p.38). In accordance with the arbitrage reasoning, any new information is immediately reflected in (Fama, 1965, p. 39).

The efficient market hypothesis became the cornerstone of the financial economics (Frankfurter and McGoun, 2002) and it has widely been used as a theoretical benchmark in the development of legal framework (Bradford and Rutten, 2006) or in the progressive convergence of accounting standards (Kothari and Lester, 2012). By assuming that all public information is already included in the financial prices, the statistical approach contrasts with the fundamental analysis presented in the previous section. However, the idea that prices are sufficient in terms of information seems to be compatible with the key assumption about information used by technical analysts (as explained in the first section). However, the most important common characteristic shared by these techniques refers to the existence of a financial referent. I will detail this common assumption in the following section.

\title{
II.4) Three methods, one reality
}

The three approaches overviewed in the previous sections are different in terms of methodology: all of them associate a value, in a different way, to the financial 
prices. Technical analysis assumes that this value can be induced from the past evolution of stock market variations, fundamental analysis tries to find this value in financial statements while the statistical approach rather associates value with the degree of randomness observed in the times series characterizing the evolution of financial markets. So doing, these three techniques refer to three different meanings of the word "information" that is required to estimate the value of financial assets. As Durkheim wrote, "value of things depends, not only on their objective properties, but also on the opinions held about them. Doubtless, these opinions are partly determined by the objective properties; but they are also shaped by many other influences" (Durkheim, 1975 [1908], p.220). The three approaches evoked above deal with different aspects of these influences.

For fundamental analysts, the value of a security is hidden in the shadow of what is not directly seen (i.e. the value is not in the observed price but somewhere in the financial statements). In this context, the idea of information refers to way of aggregating all accounting indicators and systematic recording of economic life of the companies. For technical analysis, the value is in what is recurrently observed the evolution of the financial prices. In other words, the notion of information is directly associated with the visual ability of analysts to see (literally) the emergence of a specific patterns in the stock market variations. Finally, statistical analysis explicitly studies price variations in terms of risk by considering that the value of a security is in its statistical characteristics (standard deviation, mean etc.). In this perspective, the concept of information is defined in terms of probabilistic combination of securities in order to diversify the portfolio and/or have a better return than the market.

Despite the dissimilarity evoked above, these three ways of collecting information about financial markets have a common point: all of them assume that financial prices refer to something. So doing, these three traditions implicitly adopt an objectivist or naturalizing perspective (Orlean, 2008). All analysts whatever their methodological orientation consider that financial prices refer to an existing no strictly financial entity ${ }^{16}$ outside the markets. The three approaches overviewed above recognized that financial prices also are related to interacting things outside the organizational structure in which they are estimated - the only point on which the three methods diverge refer to the way of dealing with the link between these financial prices and the outside referent. Fundamental analysts consider that this link can be found in the financial statement while technical analysts or financial economists rather think that this link is included respectively in visual recurrent patterns or statistical characteristics of stock market variations. So doing, these three approaches deals with a classical way of defining the notion of information that can be summarized as a "fact provided or learned about something" (Oxford Dictionary). Although the three methods do not associate the same meaning to the word "fact" and the fact they differ on the way of learning/providing these facts,

\footnotetext{
${ }^{16}$ By financial entity, I mean all usual financial concepts such as value, return, price, liquidity etc.
} 
it is worth emphasizing that all of them agree with the idea that financial prices refers to "something" making the concept of "information" useful for all investment decision making process. The following section will analyse the computerization of the financial markets and its consequences on the ability of financial prices "to refer to something".

\section{Algorithms and hyper-reality in finance}

Since the eighties, the greatest stock exchanges have been automated and auctions have been replaced by quotations determination algorithms ${ }^{17}$. Technically, such an electronic trading platform is an automated market which exercises some of all of the following functions : an "electronic order routine (the delivery of orders from users to the execution system), an automated trade execution (the transformation of orders into trades), an electronic dissemination of pre-trade (bid/offer quotes and depth) and post-trade information (transaction prices and volume data)" (Committee on the Global Financial System, 2001).

First, the electronic trading has profoundly revolutionized the functioning of the financial markets and the large diffusion of computers has directly contributed to the financialization of the concept of value (Arvidsson, 2009). For a few years, the organizational consequences of this technological evolution have been studied in an increasing literature (Fourcade and Khurana, 2009). For instance, Jiang, Tang and Law (2002) explained that the electronic trading has increased the operational and informational efficiency of the markets while it reduced transaction costs. Tsang (1999) compared between the traditional open outcry trading system with the automated trading system to show how the latter have increased the liquidity and the transparency of markets. This positive impact on efficiencyltransparency is also discussed by Jiang, Tang and Law (2002) who wrote that the automated system

"offers a greater transparency of the order book on prices and volumes way from the best bid and ask, which can reduce information asymmetry and provide more information for market-maker to manage their inventory exposure more effectively" (Jiang, Tang and Law, 2002).

Except the fact that the implementation of an automated system is quite expensive, no real drawbacks have been underlined in the mainstream literature devoted to the computerization of financial markets. In this context, the issue of information is crucial and, it is more and more related to the use of computerized data. At first sight, the implementation of an automated system allows a better

\footnotetext{
17 "An algorithm is a set of finite and recurrent rules or instructions which can be executed by a machine. A quotation algorithm executes the orders according to an auction process and in accordance with a set of priorities", in Muniesa (2000).
} 
recording appropriate for a statistical analysis of financial data. It is worth mentioning that, the statistical approach enhanced by the academic mainstream (evoked in the previous section) played a key role in the evolution of financial practices by providing pragmatic rules about investments ${ }^{18}$. These rules have been progressively widespread in financial profession to the point that they have even been automated in the recent computerization of financial sphere (MacKenzie, 2006, Muniesa, 2007). I will detail this point hereafter. The 1980s witnessed the replacement of traditional open outcry trading system by an algorithms-based system. More precisely, each financial marketplace has since then been equipped with an electronic trading platform on which a large part of usual financial transactions can be automatically generated by "clever algorithms" as illustrated on the graph hereafter.

\section{Rise of the machines}

Algorithmic trading, \% of total trading
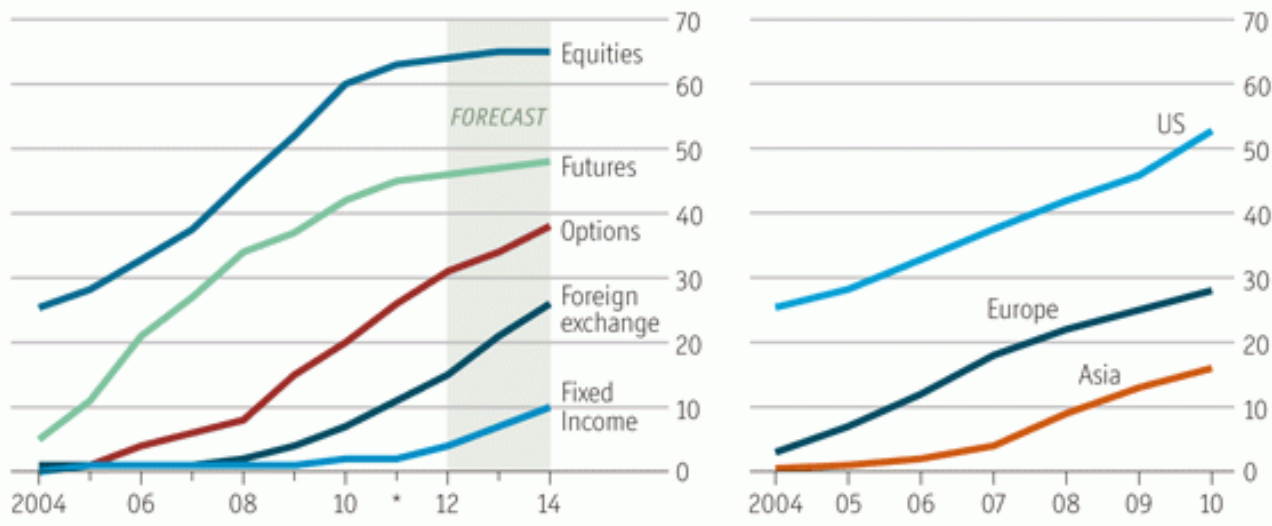

Figure 1: Importance of algorithmic trading - Source: The Economist $\left(25^{\text {th }}\right.$ February 2013)

Figure 1 shows the growing importance of automatic trading in every part of the world. While almost $70 \%$ of equities are already algorithmically traded, an increasing trend is observed for the other (less liquid) categories of financial assets. In other words, one observe an increasing automation of financial markets consistent with what Baudrillard $(1968$, p.215) called a "techneme" (i.e. automated object that tends to be more and more independent from human actions). Automatic trading is a very convenient way of organizing financial markets and it is a technical way of improving their efficiency (Jing, Tang and Law, 2002). However, as Dupuis (1992, p. 50) explained it this computerization also results from a certain ideological image of the market presented in the

\footnotetext{
${ }^{18}$ See Poitras (2000) or Betze and Spieser (2005) for a historical analysis financial practices.
} 
famous Black's article $(1971)^{19}$. In the same vein, Muniesa $(2000,2007)$ explained that the automated conception of the market corresponds to the neo-classical (mainstream) idea of a perfect market in which financial prices include all public information in order to prevent arbitrage. In other words, this way of integrating the technological progress in finance results from a specific perception of what should be a market. The mainstream finance (statistical approach) is mainly founded on the efficient market hypothesis which explicitly refers to the notion of "perfect market" that served as benchmark in the computerization process of each marketplace. By increasing the liquidity, the operational and informational efficiency and the transparency of the market while reducing the transaction costs, automatic trading represents the best way of making real markets closer to our idealized conception of the efficient market. In this vision, the technological progress seems to be used to create a market close to the idea of "perfect market" that we find in our theoretical textbooks. Mackenzie (2006) showed that this "theorisation" 20 of financial practices existed before the computerization of markets through what he called the "performativity" of models. This performativity was actually the first step towards a self-referent finance because this dimension has afterwards been enhanced by computers which gave the opportunity to create an automated projection (implementation) of theory that appears to be what Baudrillard (1994) called a "hyper-reality" (that claim has been studied in more details in McGoun, 1997; Macintosh, 2003; Schinckus, 2008, 2016; Balwin, 2012, 2015).

The concept of "hyper-reality" was used by Baudrillard (1994) to characterize the contemporary evolution of our modern society which is increasingly saturated with images, signs, codes, symbols and technology. For Baudrillard, such as situation exaggerate the real to the point that this phenomenon might create new realities detached from its original form. Whereas performativity requires human interventions (Mackenzie, 2006; Millo and Mackenzie, 2009) evoked above, the financial hyper-reality can be seen as a computerized imaginary construction of financial markets where no human intervention is required anymore. In this section, I argue that the growing computerization of financial markets generated a hyper-reality in which financial prices do not refer to "something" anymore. In this context, the assumption that the value of an asset can objectively be estimated makes no sense anymore. The hyper-reality is no longer about a referential being, it is a model-generated real with no referent - "it is about the substitution of reality with the signs of reality" (Baudrillard, 1994, p.11). In other words, prices given by the market do not follow economic reality but they shape the economic reality. Consequently, the difference between fundamental value and the observed prices loses it meaning (Orlean, 2008) and this process inverses the

\footnotetext{
${ }^{19}$ For further details on the ideological dimensions of financial economics, see Frankfurter and McGoun (1996, 1999), Jovanovic (2001).

${ }^{20}$ See also Orlean (2008) for this "process of objectification" of financial reality.
} 
referent and the sign since the price (that is supposed to be the sign of a referential value) became the referent of the fundamental value that will be used as a sign in the investment strategies. This phenomenon generated a very specific corpus dealing with hyper-reality in finance (McGoun, 1997; Hetz, 2000; Schinckus, 2008; Baldwin, 2012; 2015). While these works mainly focused on the description of this hyper-reality, this paper is more about the explicitness of this phenomenon. What is for financial information to implement (and accept) such phenomenon? After having illustrated this claim with a recent example, I will discuss in the following section the consequences of such as evolution on the three methods of collecting information about financial markets that I presented in the first part of the paper.

Algorithms used in the computerization of financial sphere represent the most evolved form of an implemented rationality. In accordance with the financial mainstream, computers and algorithms are supposed to behave rationally; to identify the arbitrage opportunity and to take the "right decision" quicker than human abilities can take a decision (Mackenzie, 2006; Muniesa, 2007). The theoretical argument behind this computerisation refers to the necessity to exploit all arbitrage opportunities in order to bring financial markets to the equilibrium (Jiang and al., 2002). However, one can find counter-examples in which the socalled computerized perfect market may generate a paradoxical "non-human irrationality" contributing to the creation of a new financial reality detached from the economic one. I am going to illustrate this claim now.

On Thursday the $6^{\text {th }}$ of May 2010, the Dow Jones Industrial Average plunged about 9\% within less than five minutes. That fall was due to "the combined selling pressure from the sell algorithm" (SEC, 2010) which generated a "hot-potato" volume effect by quickly buying and reselling contracts. According to a SEC report (2010), more than 27000 contracts ( $49 \%$ of total trading volume) were traded on the market between $2 \mathrm{~h} 45: 13 \mathrm{sec}$ and $2 \mathrm{~h} 45: 27 \mathrm{sec}$. Because algorithms have been created to react to newslevents faster than human eyes can scan them, we may observe "unreal situations" in which half of the market can be traded in 15 seconds! A very rapid and deep fall (called "flash crash") in security prices may occur within an extremely short period. It is hard to believe that a large part of the American economy (to what the DJIA index is supposed to refer) can really lose a so significant percentage of its value in few seconds - this vision is a strictly financial perspective totally disconnected from the economiclsocial reality. Historically, financial markets are supposed to contribute to economy by offering an equilibrium between companies in need of capital and cash holders (Shiller, 2008). In such context, financial markets and productive economy were supposed to be connected. In the past few years, a lot of critics (Colander et al., 2009; Stiglitz, 2010; Shiller, 2012) questioned whether wealth created by financial markets can really be distributed beyond its immediate recipient (the financial 
industry). The financial sphere strangely appeared more and more as a selfsufficient area disconnected from society and promoting a predatory capitalism focused on short-term profit. Shiller (2008) mentioned that there is no explanation for a continuously high growth of returns in the financial sphere when real economic growth is stagnant. Regarding this disconnection, Aoki and Yoshikawa (2007) observed an increasing difference between the statistical distributions characterizing the evolution of financial variables (stocks returns, foreign exchange etc.) and those describing economic fundamentals (growth of GDP etc.) while financial variables usually follow a power law behavior, economic ones are rather characterized by an exponential distribution ${ }^{21}$. This observation is consistent with the idea that financial sphere appears more and more disconnected from their underlying economic fundamentals. Extreme variations and crashes are common in finance (Kindleberger 1989) but, in the past, they were the result of human behaviours and they historically appeared on a period of several days. In contrast, flash crashes appear in few seconds because they don't result from human actions. Concretely, this kind of crashes result from a computerised excitement of the market by algorithms which creates a loop effect in buying and selling trends generating a sharp fall in security prices as illustrated on the following graph,

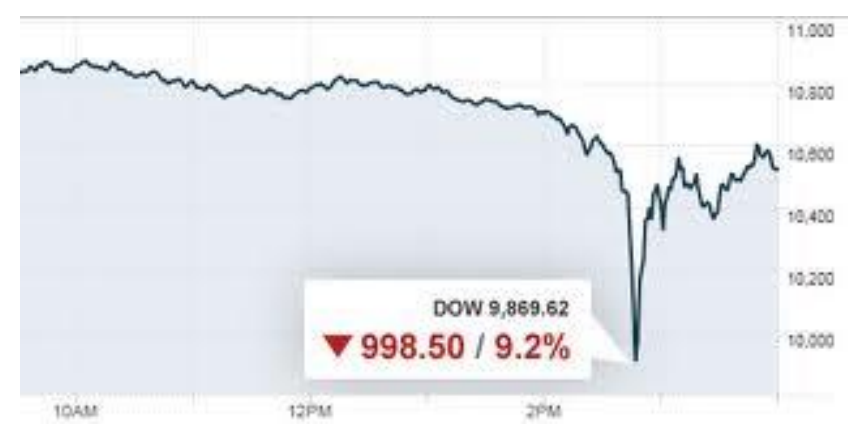

Figure 2: Flash crash on the Dow Jones Industrial Average Index (Madrigal, 2010)

The figure 2 illustrates the decrease of Dow Jones Index resulting of the fall in security prices on the $6^{\text {th }}$ May 2010 . We can observe the important decrease of the index (combined with an important trade volume meaning that algorithms were operating at the same time within a very short period of time) creating a paradoxical situation in which we had a market without reality (no economic justification) neither trader (automated trade). Flash crashes transformed the financial market into a nullspace of simulacra where all real-economic justifications have been dissipated. This hyper-reality enhanced by the computerization of financial markets does not result from the potential economic reality but it paradoxically influences the real productive sphere. We observe therefore an inversion of the effect-cause pattern. Indeed, after having been

\footnotetext{
${ }^{21}$ See Aoki and Yoshikawa (2007), for further details on that topic.
} 
emancipated from economic reality (historically the cause of the existence of financial markets), automated prices progressively directly influence the economic situation of companies ${ }^{22}$. The effect became the cause in accordance with the Baudrillardian idea according to which the hyper-reality does not model the reality but it precedes the real (i.e. the hyper-reality becomes the benchmark for what it is supposed to refer).

This idea of hyper-reality calls into question the notion of models and it implies an interesting way of implementing knowledge: in opposition to the classical (Popperian) way of doing science in which models are applied to reality by adjusting the assumptions in order to improve their adequacy with this reality, financial computerization appears as way of transforming the reality to make it closer from theory. In other words, computerization gives the opportunity to adapt financial reality to the original theoretical model ("perfect market"). In this context, the pertinence of information remains a crucial issue: what is the consequence of this growing computerization of financial sphere on what we know or what we can say about financial prices? I will deal with this aspect in more details in the following sections.

\section{And the information in all of this?}

The growing computerization of financial markets raises some questions on the way of collecting information about financial prices. In the light of what has been presented in the previous section, one can wonder what is impact of this new hyper-real finance on the way the financial information is constructed and distributed.

Now that financial markets are computerized, tens of thousands of transactions can be observed and recorded in few seconds (Engle and Russell 2004). At first sight, this evolution is a good thing for the investment decision making process since a systematic record of all stock market variations generates databases that can then be used as a source of investigation for decision makers. No doubt that the increasing number of data combined with the fact it is become easier to access them create an information-oriented context. Two aspects of this reality can be studied: 1) the management of this information explosion that might complicate the investment decision making process and, 2) the nature of the information dealing with what does inform refer to. In this section, I will focus my attention

\footnotetext{
22 In a sense, this process inverts the Platonic metaphysics since the image (financial prices) becomes the model for "truth". I could also mention how the development of a new intranet for specialized traders contributed to a financial crash in Croatia in 2008 (Sajter and Coric, 2009) or the impact of the recent Twitter crash in which an erroneous tweet generated a brief plunge of 130 points from the Dow Jones Industrial Average. For further information about this, see Schinckus (2008) or Stewart (2012).
} 
only on the latter aspect ${ }^{23}$. The previous section illustrated how the stock market variations can be detached from all economic referent. Seventy percent of the decisions made on the securities markets are taken by algorithms not based on economic reality but rather on strictly statistical considerations assuming that all economic information is included in the price. In this perspective, it is crucial to question the digitally produced information and what this information is supposed to refer "outside of the computers".

On this point, the case of flash crash is a telling example of what information means today on the stock markets. By liberating financial prices from all economic referent, the computerization of financial markets unwillingly contributed to an increasing gap between financial and economic spheres. Nowadays, the financial sign (price) results from a statisticallcomputerized treatment of stock market variations. In this perspective, the assumption according to which all information (referring to economic reality) is included in the price (sign) becomes therefore problematic and even irrelevant. Fama (1965) gave an economic justification to the idea that all information could be included in prices. However, the example of the flash crash illustrated how the evolution of financial prices does not refer to any economic information but rather to a computerized loop effect. In other words, the semantic translation (i.e. economic interpretation) of financial data become more difficult complicating the investment decision making process. This evolution of financial market is very interesting because the computerized implementation of a specific way of thinking information (i.e. all information is included in the prices) led to the dilution/disappearance of information: the current context with its Twitter $\backslash$ flash crashes calls for a new conceptualization of the notion of information that would integrate the fact that the digitalized way of generating information is also a part of the information.

The way of collecting information about financial markets that are based on the assumption according to which the financial prices are totally independent from the socialleconomic fabric can be presented as self-referent stories (statistical approach and technical analysis). Indeed, scholars involved in such approaches consider that the quotations refer to nothing else than themselves, that there is nothing behind the quotations. In other words, social behaviors, human interactions and the economic reality appear to be neutralized through the use of algorithmic rules $^{24}$. The computerization of financial markets allowed the implementation of the assumption according to which all prices are self-sufficient

\footnotetext{
${ }^{23}$ See Ramaswamy (2006) about the development of a financial information system to accumulate $\backslash a n a l y s e$ financial data for optimal planning \decision.

24 It is also worth mentioning that this "neutralization" of the social \economic dimension of the financial reality also played a key role in the emergence of new fields such as "econophysics" or "neuronal finance". While the first consists in applying in finance models developed in physics in which quotations are studied as if they behaved like gas molecules or atoms (See Jovanovic and Schinckus, 2016), the latter rather develop pricing algorithms by considering that stock markets variations behave like electric inputs and outputs.
} 
in terms of information. Despite that this assumption is shared by financial mainstream and technical analysis (for different reasons), its computerized implementation generated unexpected situations for which our usual way of defining information does not make sense anymore. The self-referential prices (for example, a flash crash) tends to dilute the real economic information (the productive sphere did not lose $10 \%$ of its value in few seconds) by acting as if the situation were true. For Baudrillard (1994), such self-referential systems are "simulacra" based on a "reality principle" in order "to hide the fact that what we actually take to be real are only simulations" (Baudrillard, 1994, p.12). Information technology might have contributed to strengthen this reality principle evoked by Baudrillard. However, the notion of hyper-reality showed the unthought effects of the computerization process since it illustrates how the materialization of the mainstream knowledge (based on the efficient market hypothesis) can also create a consequence in total contradiction with a key assumption of this knowledge. Specifically, while the self-reference nature of finance prices is in line with the theoretical idea that they integrate all information available on the market, the emergence of a flash crash indicates that the market does not evolve rationally in line with a perfect bell-shaped curve. In the same vein, from a chartist point of view, the self-referentiality of financial prices is acceptable but the unexpected appearance of flash crash seems to be an un-thought and un-thinkable event that contrast with the usual chartist practices.

In the first section, I also evoked fundamental analysis which tries to give a meaning to quotations beyond the financial prices. This way of collecting information about financial markets tries to understand what is hidden behind the stock market variations ${ }^{25}$ by emphasizing the accounting dimensions of the financial reality. Such approach is largely based on a representation of investors who try to discover what Orlean (2008) called a "salience" (i.e. "the opinion which imposes itself on the greatest number of players as expressing the opinion of the group" Orlean (2008, p.7). In this context, accounting is often presented as a structured language that allows actors to formalize the economic life of companies and, therefore, to estimate their financial value. Macintosh et al. (2000) and Macintosh (2003) investigated the importance of sign and referent in language of accounting. Accounting theory and practices usually associate accounting signs with real economic activities (purchases process, production etc.) made by a specific economic entity. Afterwards, an evaluation of these activities through accounting models $\backslash$ ratios provides accounting earnings which, idealistically, are supposed to determine the financial value and therefore the price of the stocks traded on the financial markets. In other words, financial prices are supposed to be the sign of an economic referent while accounting is playing the role of signifier (i.e. the tool through which the meaning is created). However, as illustrated in the

\footnotetext{
${ }^{25}$ In this category, one could also mention the other approaches such as behavioural finance or social studies of finance, for instance.
} 
previous section, financial prices observed on the stock markets can be disconnected of these real economic activities.

Macintosh et al. (2000, p.35) explained that "accounting standard setters are embracing the use of the market values on company sheets". Actually, marketbased accounting is promoted in IFRS standards (Chane-Alune, 2006; Laux and al. 2010; Kothari and Lester, 2012) and it has been issued as the US accounting standard (FAS157) in 2006. However, although a promotion of a more market-based accounting is often associated with the "most relevant measure" or with the estimation of the "fair value" for financial instruments, it can also contribute to the disconnection between the financial sphere and the economic (productive) reality. As evoked in the previous section, the market price of financial assets are estimated through statistics based algorithms whose computerized implementation tends to transform the financial markets into "a perfect competitive sphere" (Muniesa, 2000). In this perspective, a more market-value based accounting would contribute to this construction of an ideal financial hyper-reality in which "neither the accounting sign [earning] nor the financial market sign [price] appear to be grounded in any external [economic] reality" (Macinstosh et al. 2000, p.36). This situation is problematic for accountants since the value tends to become more and more a copy of a copy (market price) produced by a computerised simulation of a specific imaginary solution (i.e. efficient market hypothesis). Consequently, the notion of fair value also loses its meaning - indeed, if the fair value refers to the price agreed between two market participants in an orderly transaction and that this price is algorithmically estimated through a computerised simulation of the idea of efficient market then there is an urgent need for debates in order to preserve a market-based accounting valuation founded on an economic referent.

Accounting evaluation is supposed to deliver the appropriate information for a correct decision making process. Accounting contributes to form conventions about the financial value of assets. In a context of hyper-reality evoked in the previous section, the self-referent computerized market value based accounting would have no economic neither humane justification. Indeed, algorithms leads to a particular self-referentiality since the assets value just results from a fast and shared (by algorithms) computerized treatment (taking the form of a no-end selling loop) of a signal leading the market to a flash crash. This algorithmic self-referentiality contrasts with the self-referential interactions emphasized by Orlean (2008) since it is not due to a widely dispersed opinion of agents. More precisely, as Orlean (2008) explained it, beyond the economiclaccounting evaluation, fundamental analysis, required a collective adherence that will form financial conventions. This process will endure "as long as what is produced is in accordance with predictions and satisfactory for investors" (Orlean, 2008, p. 12). This dynamics does not work anymore with the algorithmic self-referentiality illustrated above, simply because (human) actors does not even have time to form a convention about the market 
and its evolution. Decisions (and positions on the market) are then algorithmically generated faster than what human investors could do. Such context makes fundamental analysis irrelevant since it dilutes the traditional concept of accounting information. Financial prices do not refer to accounting records of economic activities anymore but rather to an endless self-referent combination of sign (price) and signifier (accounting ratios) without any economic referent.

\section{Conclusion}

The computerization of financial markets changed the nature of information. While the number of data increases providing a bigger source of information, the reality to what this information refers tends to disappear gradually. The three usual ways of collecting information about financial markets evoked in this essay assume that; 1) financial prices refer to "something else" than themselves and, 2) the future is either the reflect (technical analysis) or a deformation (fundamental analysis and statistical approach) of the past. However, the contemporary evolution of financial sphere creates a situation in which future events can have "no-thing" to which they refers (i.e. flash crash) meaning that our usual way of dealing with information to reduce uncertainty must be revised. Information technology has been implemented in the financial sphere without adjusting our way of defining/using the concept of information. Today, computerization increases the uncertainty of these markets not because it increases their unpredictability but rather because it led to the emergence of unexpected facts that has not happened in the past. These un-thought consequences of computerization of financial markets emphasizes the intrinsically uncertain nature of financial information. However, this paper illutrates that this uncertainty can be increased by the way of collecting and dealing with financial data. Such as evolution of financial markets calls for a reflection on the way the notion of information is defined and used in finance. This article aimed at initiating such as discussion. Beyond this informational aspect, the algorithmization of financial markets also paves the way to a reflective questioning about how we can intervene in events when they are simulated and replaced by pseudo-events (i.e. flash crashes are not based on an economic reality). This conclusion echoes to the call for pluralism in finance repeated by several authors (Bay and Schinckus, 2012; Segot-Lagoarde, 2016): the ambiguity of the financialization of society is such that a combination of conceptualltheoretical perspective can offer an acceptable understanding of the phenomenon. In the light of the analysis suggested in this paper, financialization generates an urgent need for debates on the way we materialize the traditional theoretical concepts (information, market participants etc.) developed in financial economics. 


\section{References}

Abarbanell J. and Bushee B. (1997), "Fundamental Analysis, Future Earnings and Stock Prices", Journal of Accounting Research, vol. 35, no.1, 1-24.

Aoki, M, and Hiroshi Y. (2007), A Stochastic Approach to Macroeconomics and Financial Markets. Cambridge, UK: Cambridge University Press

Allen F. (1999), "The role of information in financial and capital markets", Working paper, Wharton School, University of Pennsylvania.

Arvidsson, A. (2009) "The Ethical Economy: Towards a Post-Capitalist Theory of Value", New Left Review, 97: 13-29

Balwin J. (2012), Financial Crash and Hyper Real Economy, Williamsburg: Books Division.

Baldwin J. (2015), Baudrillard and Neoliberalism, International Journal of Baudrillard Studies, vol. 12, no 2.

Baudrillard J. (1968), Le système des objets, Paris : Gallimard.

Baudrillard J. (1994) Simulacra and Simulation, translated by Sheila Faria Glaser, Michigan, The University of Michigan Press.

Bay Th. And Schinckus C. (2012), "Critical Finance Studies: An interdisciplinary perspective”, Journal of Interdisciplinary Economics, January, vol.24: 1-6.

Belze L. and Spieser Ph. (2005), Histoire de la finance, Paris: Vuibert

Bernstein, P. (1992). Capital ideas : the improbable origins of modern Wall Street. New York and Toronto: Free Press; Maxwell Macmillan Canada; Maxwell Macmillan International.

Black, F. (1971), Toward a fully automated stock exchange. Financial Analysts Journal 27 (4), 1971.

Bulkowski T. (2005), Encyclopedia of Chart Patterns, Wiley, New York.

Cartwright N. (1999), The Dappled World: a study of the boundaries of science, Cambridge: Cambridge University Press.

Chane-Alune E. (2006), Accounting Standardization and Gouvernance Structures, Working paper $\mathrm{n}^{\circ}$ 0609, University of Liège.

Colander D., H. Follmer, A. Haas, M. Godber, K. Juselius, A. Kirman, T. Lux, and B. Slot, (2009), "The financial crisis and the systemic failure of academic finance," Critical Review: A Journal of Politics and Society, Vol 21 (2-3), 249-267.

Committee on the Global Financial System, 2001. The Implications of Electronic Trading in Financial Markets. BIS (Bank for International Settlements), Paper 12.

Cootner, Paul H. (1964). The random character of stock market prices. MIT Press

Cornell B. and Rutten J. (2006) Market Efficiency, Crashes andSecurities Litigation, 81 Tulane. Law Review. 443, 443. 
Dupuy J-P (1992), Libéralisme et Justice sociale : le sacrifice et l'envie, Paris: Hachette.

Durkheim E. (1975 [1908]), Éléments d'une théorie sociale, Paris: Les Éditions de Minuit, coll. "Le sens commun".

Engle R. and Russell J. (2004), Analysis of high frequency financial data. In University of Chicago Working Paper.

Fama, E. (1965), "The Behavior of Stock-Market Prices." Journal of Business 38 (1):34-105.

Fourcade, , and Khurana R. (2009), "From Social Control to Financial Economics: The Linked Ecologies of Economics and Business in Twentieth-Century America." annual meeting of the SASE Annual Conference, Paris.

Frankfurter G. \& McGoun E. (1996), The Methodology of Finance : What it is and What it can be, London: JAI Press.

Frankfurter G. \& McGoun E. (1999), «Ideology and the Theory of Financial Economics », Economic Behavior \& Organisation, vol. 39, 159-177.

Galison P. (1997), Image and Logic: a material culture of microphysics, Chicago: The University of Chicago Press.

Gann W (1923) Truth of the Stock Tape: A Study of the Stock and Commodity Markets with Charts and Rules for Successful Trading and Investing, Financial guardian Publishing Company, 1923

Hamilton W.D. (1922) The stock market barometer, Harper, New York

Hertz E. (2000), “Stock Markets as simulacra”, Tsantsa, vol. 5, 40-50.

Hoffland D. (1967), “The folklore of Wall Street”, Financial Analysts Journal, Vol. 23, No. 3, 85-97.

Jiang, G., Tang, N., Law, E., 2002. Electronic trading in Hong Kong and its impact on market functioning. BIS (Bank for International Settlements) Papers 12.

Jovanovic, F. (2001), "Pourquoi l'hypothèse de marche aléatoire en théorie financière? Les raisons historiques d'un choix éthique." Revue d'Economie Financière 61:203-211

Jovanovic F. (2008), "The Construction of the Canonical History of Financial economics", History of Political Economy, vol.40, no 2: 213-242.

Jovanovic, F., ed. (2009), L'institutionnalisation de l'économie financière : perspectives historiques. Vol. 20: Revue d'Histoire des Sciences Humaines.

Karl A. (2013), "Bank talk: performativity and financial markets", Journal of Cultural Economy, vol.6 (1), p.61-77.

Kindleberger, C. (1989). Manias, Panics, and Crashes: A History of Financial Crises. London: Macmillan.

Keynes J.M. (1937), “The General Theory of Employment”, Quarterly Journal of Economics, vol. 51, $\mathrm{n}^{\circ}$ 2, pp. 209-223. 
Kothari, S. P., and Lester R. (2012), "The Role of Accounting in the Financial Crisis: Lessons for the Future.” Accounting Horizons, vol. 26 (2), 335-351.

Laux, C., Leuz, C. (2010), "Did Fair-Value Accounting Contribute to the Financial Crisis?" Journal of Economic Perspectives, vol. 24, 93-118.

Lagoarde-Segot, T., (2016), “Financialization: towards a new research agenda", International Review of Financial Analysis, forthcoming.

Latour B. (1987), Science in action: how to follow scientists and engineers through society, Milton Keynes: Open University Press.

Lépinay, V.-A. (2007a). "Decoding Finance. Articulation and Liquidity around a Trading Room”. In D. Mackenzie, F. Muniesa \& L. Siu (Eds.), Do Economists Make Markets? On the Performativity of Economics (pp. 87-127). Princeton/Oxford: Princeton University Press.

Lépinay, V.-A. (2007b), “Parasitic formulae: the case of capital guarantee products's, in M Callon, Y.Millo and F. Muniesa, Market Devices, Oxford: Blackwell.

Leigh S. (2002), Essential Technical Analysis: Tools and Techniques to Spot Market Trends, Wiley, New YorkMcGoun, E., 1997. Hyperreal finance. Critical Perspectives on Accounting 8 (1-2), 97-122.

Lev B. and Thiagarajan R. (1993), "Fundamental Information Analysis", Journal of Accounting Research, vol. 31, no.2, 190-215.

MacKenzie, D. and Y. Millo Y. (2003), 'Constructing a market, performing theory: The historical sociology of a financial derivatives exchange', American Journal of Sociology, vol. 109 (1), 107-145.

Mackenzie D. (2006), An Engine, Not a Camera: How Financial Models Shape Markets, Cambridge: MIT Press.

Macintosh N., Shearer T., Thornton D., Welker M. (2000), "Accounting as simulacrum and hyperreality: perspectives on income and capital", Accounting, Organizations and Society vol. 25(1):13-50.

Macintosh, N. B. (2003), 'From rationality to hyperreality: Paradigm poker', International Review of Financial Analysis, vol. 12 (4), 453-465.

Madrigal A. (2010), "No Easy Tech Explanation for What Caused Wall St. 'Flash Crash'” The Atlantic Magazine, $14^{\text {th }}$ of July.

Markowitz, H. (1952). "Portfolio Selection." Journal of Finance 7 (1):77-91

Mattessich R. (2003), "Accounting representation and the onion model of reality: a comparison with Baudrillard's orders of simulacra and his hyperreality", Accounting, Organizations and Society, vol. 28:443-70.

Millo, Y. and MacKenzie D. (2009), "The usefulness of inaccurate models: Towards an understanding of the emergence of financial risk management." Accounting, Organizations and Society, 34, 638-653. 
Muniesa F. (2000), "Un robot walrasien. Cotation électronique et justesse de la découverte des prix", Politix, vol. 13, 121-154.

Muniesa F. (2007), "Market technologies and the pragmatics of prices", Economy and Society, vol. 36, no.3, 377-395.

Muniesa, F., (2014), The Provoked Economy: economic reality and the performative turn. London: Routledge.

Oberlechner, Th. (2001), "Importance of Technical and Fundamental Analysis in the European Foreign Exchange Market," International Journal of Finance and Economics, 6, 81-93.

Orléan, A. (2008), "Knowledge in Finance: Objective Value versus Convention", in Richard Arena and Agnès Festré (eds.), Handbook of Knowledge and Economics, Edward Elgar.

Park C.H. and Irwin S. (2004), "The profitability of Technical Analysis: A Review", AgMas Research Paper, no 4. University of Illinois at Urbana-Champaign.

Poitras, G., (2000), The Early History of Financial Economics 1478-1776. Edward Elgar, Cheltenham, UK.

Poitras, G. (2009), "From Antwerp to Chicago: The History of Exchange Traded Derivative Security Contracts." Revue d'Histoire des Sciences Humaines 20:11-50.

Power M. (2010), "Fair value accounting, financial economics and the transformation of reliability", Accounting and Business Research, vol. 40, no.3, 197-210.

Preda A. (2009), Framing Finance, The University of Chicago Press, Chicago.

Ramaswamy M. (2006), On the phenomenon of information dilution, Issues in Information Systems, vol. 7, no. 2, 289-292.

Rhea R. (1932), Dow theory, Barrons, New York.

Salomon, G. (1979). The interaction of media, cognition and learning. San Fransisco: Jossey-Bass

Sajter D. \& Ćorić T. (2009) “(I)rationality of Investors on Croatian Stock Market”, EFZG Working Papers Series 0901, Faculty of Economics and Business, University of Zagreb.

Schinckus C. and Christiansen I. (2012) "Visual Finance" (with I. Christiansen), Journal of Interdisciplinary Economics, vol.24, 173-194.

Schinckus C. (2008), "The Financial Simulacrum", Journal of Socio-Economics, 2008, Vol 73/3, 1076-1089.

Schultz H. (1925), "Forecasting Security Prices", Journal of the American Statistical Association, Vol. 20, no150, 244-249.

Sewell M. (2008), “Technical Analysis”, Working paper, University College London.

Shiller R. (2008), The Subprime Solution, Princeton: Princeton University Press.

Shiller R. (2012), Finance and the Good Society, Princeton: Princeton University Press.

Stewart I. (2012), 17 Equations that Changed the World, London: Profile Books 
Stiglitz J., (2010), Freefall: America, Free Markets, and the Sinking of the World Economy W.W. Norton \& Company.

Tsang, R., (1999), Open outcry and electronic trading in futures exchanges. Bank of Canada Review, Spring.

Whitley, R. 1986. "The Rise of Modern Finance Theory: its characteristics as a scientific field and connection to the changing structure of capital markets." In Research in the History of Economic Thought and Methodology, edited by Warren J.

Samuels, 147-178. Stanford: JAI Press Inc. 